\title{
La presencia norteamericana en el agro sinaloense en la primera mitad del siglo $\mathrm{XX}$
}

\author{
Hubert Carton de Grammont \\ Instituto de Investigaciones Sociales \\ Universidad Nacional Autónoma de México
}

\section{Resumen}

El presente artículo nos presenta el panorama del agro sinaloense desde finales del siglo XIX hasta los años treinta, en que el gobierno federal realizó el reparto agrario. Los extranjeros tenían el control económico tanto sobre las tierras, como sobre la producción de cultivos, los ingenios azucareros, las concesiones sobre las redes ferroviarias, etc. En reacción contra la política porfirista de dar facilidades a la inversión extranjera en el país, en particular a la agricultura, los gobiernos pos-revolucionarios se vieron en la necesidad de limitar la influencia y el poder de los extranjeros, especialmente de los norteamericanos en la economía nacional. Después del reparto cardenista se prosiguió al reparto agrario con la apertura de los distritos de riego y la aplicación de la Ley Federal de Aguas. A lo largo de estos años, las compañías norteamericanas salieron poco a poco del sector de la producción agrícola. Sin embargo, al cabo del tiempo, a partir de los sesenta las agroindustrias internacionales volvieron a penetrar con tal fuerza que ahora en gran medida la agricultura mexicana está dominada por el capital agroindustrial extranjero, esencialmente norteamericano.

Palabras clave: reforma agraria, reparto agrario, producción agroindustrial, inversión extranjera.

\begin{abstract}
This article presents the status of Sinaloa's agriculture by the late XIX century up to the 30's, when the federal government distributed agriculture lands. Foreigners had the economical control over the lands, over cultivation production, sugar mills, over the permits to use the railroads system, etc. Post-revolutionary governments limited the influence of foreign powers, mainly from America, upon national economics, as a measure against Porfirio Díaz' politics that promoted and accepted foreign investments in Mexico, specially on agriculture. To Cárdenas' distribution of lands, was followed by agricultural distribution, irrigation districts were opened and the Federal Water Regulation was implemented and put in force. Along these years, American corporations abandoned agriculture production in Mexico. However, some years later, during the early 60's, international agro-industrial companies came back with such a strength that, nowadays Mexican agriculture is under the domain of foreign agro-industrial capital, mainly from America.
\end{abstract}

Keywords: agricultural reform, agricultural distribution, agro-industrial production, foreing investment. 


\title{
LA PRESENCIA NORTEAMERICANA EN EL AGRO SINALOENSE EN LA PRIMERA MITAD DEL SIGLO XX*
}

\author{
Por \\ Hubert Carton de Grammont \\ Instituto de Investigaciones \\ Sociales UNAM
}

"Deben ser llamados a poblar el país y a disfrutar de oportunidades para establecer sus hogares sobre las zonas de riego, en primer lugar los mexicanos, tanto los que viven en el país como los que se han expatriado en busca de mejoramiento económico. Probablemente no bastarán nuestros connacionales para poner en explotación todas las áreas que pueden ser regadas, por lo cual habrá de recurrir, para aumentar nuestra capacidad de producción (...) a la colonización extranjera.

Pero no debemos aumentar nuestra población de cualquier modo. . . sería un grave error. Necesitamos en primer lugar saber qué es lo que queremos ser y luego poner los medios para lograrlo. Sufrimos ahora de falta de unidad social (...) La may or fuerza de cohesión es el elemento hispánico que ejerce cierta hegemonía (...) debemos procurar consolidar la hegemonía espiritual del grupo hispánico en nuestro país, debemos continuar siendo hispánico, más hispánico cada vez, si cabe.

Nuestra colonización debe ser hispánica si no queremos ser disueltos o absorbidos, es decir, si no queremos dejar de ser. Contra esa tendencia, necesaria para nuestra salvación y nuestro engrandecimiento, irán todas las colonizaciones no asimilables. No nos conviene tolerar, ni mucho menos provocar, may or heterogeneidad racial en México. En defecto de colonización hispánica en cantidades ilimitadas, pudiera aceptarse la italiana, parsimoniosamente".1

Esta fue la opinión oficial que la Comisión Nacional Agraria dio al presidente de la república, en 1928, cuando el gobierno se enfrentaba a la necesidad de colonizar los nuevos distritos de riego, recién creados en el norte del país, y refleja perfectamente bien la posición del sector oficial. En reacción contra la política porfirista, de dar todas las facilidades a la inversión extranjera en el país, en particular en la agricultura, los gobiernos posrevolucionarios se vieron en la necesidad de limitar la influencia extranjera, fundamentalmente la norteamericana, en la economía nacional. Sin duda, existían temores de una nueva anexión de los estados del norte del país a E.U.A.: la existencia de corrientes de opinión norteamericanas favorables a una mayor

\footnotetext{
- Esta ponencia forma parte de una investigación sobre el desarrollo de empresas agrícolas en el estado de Sinaloa.

'Excélsior, 22 de octubre de 1928, pp. 1 y 8. Tomado del memorándum elaborado, en 1928, por la Comisión Nacional Agraria sobre el problema de la colonización de los nuevos distritos de riego, creados por la Comisión Nacional de Irrigación.
} 
penetración en estos estados y la importancia misma del capital estadounidense en la agricultura, la minería y el comercio en el norte de México, eran elementos bastante serios como para que el gobierno se preocupara por la integridad nacional. Por eso se veŕa peligroso seguir permitiendo la colonización de tierras por extranjeros, principalmente en los estados fronterizos.

Sin embargo, no era nada fácil llevar a cabo medidas concretas para fortalecer la hispanización del país y limitar la penetración de capital norteamericano. En el territorio nacional faltaba gente preparada para lograr un verdadero proceso de colonización. Faltaba una clase campesina avanzada, modernizada, que pudiera instalarse en los territorios despoblados del Norte. Además, el gobierno no tenía dinero para emprender de inmediato y a gran escala tal tarea. ${ }^{2}$ Se necesitaba no solamente gente adecuadamente preparada, decidida a trabajar, a empezar de la nada para levantar una nueva agricultura moderna, sino gente con cierto capital para instalarse. Este colono perfecto era muy escaso en México; en donde sí se encontraba era en los estados sureños de los Estados Unidos. ${ }^{3}$ Había que organizar, entonces, el regreso de estos nacionales; debían dar el brinco de regreso por encima del río Colorado para instalarse en tierras nacionales.

La Ley Box, que en 1929 quería limitar la migración de braceros en los Estados Unidos, fue bien vista por ciertos sectores gubernamentales mexicanos porque, según ellos, era una manera de presionar a los agricultores mexicanos a regresar a su país. Fuentes oficiales preveían muy optimistamente el regreso de medio millón de familias del estado de Texas. Se esperaba que este flujo migratorio permitiría poblar la zona fronteriza del lado mexicano.

En Sinaloa, El demócrata sinaloense, periódico estatal cercano a las posiciones gubernamentales, hacía eco de estas preocupaciones, ya que este estado, aunque no se le pudiera considerar un estado fronterizo en términos estrictamente geográficos, era uno de los privilegiados para la colonización. La existencia de una planicie atravesada por once importantes ríos le dotaba de la red fluvial más amplia y mejor distribuida de la república. Hasta el principio de este siglo, la falta de comunicación había limitado su desarrollo, pero la llegada del tren primero - el Sud Pacífico-y la apertura de la carretera in-

\footnotetext{
${ }^{2}$ No solamente se consideraba que los indios eran ineptos para incorporarse a este proceso, sino que se les consideraba como una lacra, mas no un peligro, para la integridad hispánica que tanto se reivindicaba. El mismo informe que acabamos de citar dice acerca de los indigenas: "Tenemos en nuestro país una Babel india: más de veinte razas hay que hablan otros tantos idiomas distintos, que tienen otras tantas concepciones distintas de la vida y otros tantos ideales distintos nacionales, muchos de los cuales no traspasan las fronteras del valle en que la tribu vive o el margen del rio en que se halla establecida. Cada uno de esos grupos es, en realidad, una nación aparte. Viven los unos en la vecindád de los otros sin comprenderse, y naturalmente, sin amarse". (Ibidem). En pocas palabras, no pertenecen a la nación hispánica mexicana.

${ }^{3}$ Los representantes de un grupo de agricultores mexicanos establecidos en Texas que decidieron en julio de 1929 regresar a México para colonizar tierras, en el estado de Tamaulipas. En una entrevista con el presidente de la república, señalaban que: "Todos los mexicanos que vendrán de Texas han adquirido envidiables conocimientos de agricultura, asi como son todos ellos gente bien, de hábitos morigerados y con un espiritu desarrollado por el ahorro, por lo que consideran que son elementos que pueden servir de ejemplo para los campesinos". (Citado por Excélsior, 23 de julio de 1929).
} 
ternacional luego -Nogales, Guadalajara, México-, marcaron el inicio de un fuerte crecimiento económico, tal vez sin equivalente en todo el país. En una editorial del 18 de julio de 1929 este periódico afirmaba que:

"Todos los agricultores mexicanos residentes en Texas, perfectos conocedores de los cultivos, afectados por las recientes leyes migratorias de los Estados Unidos (Ley Box), y en vista de que se consolida un estado de orden y estabilidad en nuestro país, están pensando muy seriamente regresar a la República a fin de colonizar vastas regiones, si el gobierno les da facilidad para ello".

¿Cuál era la situación en Sinaloa; cuál era la influencia norteamericana en la región en esta época?

Para dilucidar estas preguntas, analizaremos el papel que tuvo el capital norteamericano en el desarrollo agrícola sinaloense a través de su participa: ción en la propiedad de la tierra y en los dos cultivos comerciales más dinámicos en este período, que fueron la caña de azúcar y el jitomate. Para terminar veremos cuál ha sido el impacto del reparto agrario sobre los agricultores y compañías estadounidenses.

\section{LA PROPIEDAD}

La presencia de agricultores en Sinaloa se fortaleció desde el porfiriato. En 1985, había 13706 agricultores en el estado, que representaban el $21.6 \%$ de la población activa en la agricultura; en 1910, su número se había incrementado a 28907 y representaba el $34.5 \%$ de la misma población; cuando a nivel nacional los agricultores representaban para las mismas fechas sólo el $9.9 \%$ y el $11.5 \%$ de la población activa en la agricultura. 4

La influencia de los norteamericanos entre los productores más importantes era notoria. En 1926 se estima que había en Sinaloa 517 propietarios dueños de tierras con una superficie promedio de más de 800 hectáreas, con un valor de más de 5000 pesos. De ellos 417 eran mexicanos, 75 norteamericanos y 25 de diferentes nacionalidades (ver cuadro 1$) .5$

Profundizando el análisis, si consideramos a todos los productores $-\mathrm{y}$ no solamente a los más grandes-, encontramos que el valor de las propiedades estadounidenses es mucho mayor que el valor de las propiedades mexicanas. Esto se debe a que los norteamericanos buscaban, para instalarse, tierras

\footnotetext{
- En las estadisticas se encuentran las categorias de hacendados y agricultores. La diferencia entre ambas categorias no es siempre precisa, ya que encontramos agricultores con grandes superficies de tierra. De todos modos las haciendas corresponden a un sistema de producción tradicional, más extensivo, basado, esencialmente, en el monopolio de enormes superficies de tierra. González, Moisés. Estadisticas sociales del parfiriato, 1877-1910, El Colegio de México, 1960.

' Departamento de la Estadistica Nacional. Sonora, Sinaloa y Nayarit, México, D.F., Imprenta Mundial, 1928.
} 
CUADRO 1. Nacionalidad de los propietarios cuya tierra tiene un valor de más de 5000 pesos.

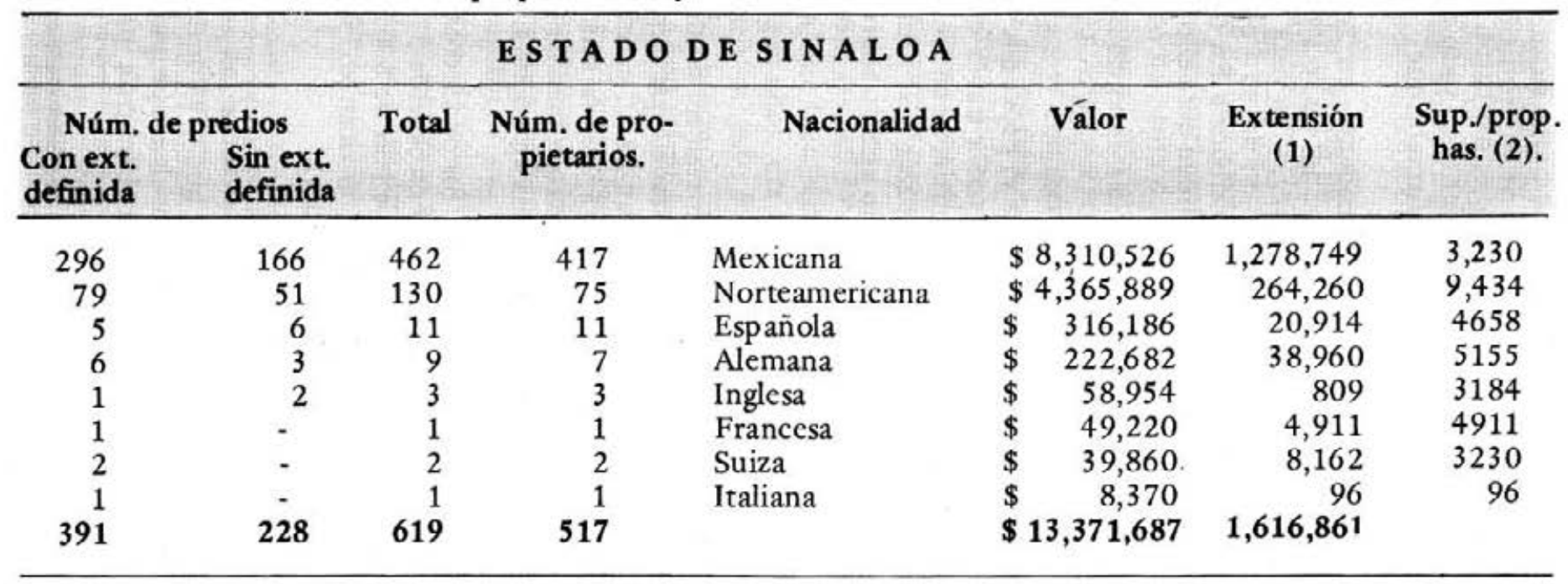

FUENTE; Departamento de la Estadística Nacional. Sonora, Sinaloa y Nayarit. México, D.F., Imprenta Mundial, 1928, pp.124.

(1) Estas cifras corresponden solamente a la extensión de los precios de los cuales se conoce su superfirie.

(2) Estas cifras son calculadas a partir del valor total de la superficie poseid a por cada grupo, aplicando el valor promedio de la tierra a nivel estatal que es de 6.17 pesos/ha. Calculado por el autor. 
de buena calidad, cerca de los ríos, y que por lo tanto sus empresas eran más eficientes (ver cuadro 2 ).

Llegamos a la misma conclusión si en vez de considerar a la superficie total consideramos sólo la superficie de tierras cultivables, o sea aptas para la agricultura, en manos de extranjeros (cuadro 3 ).

Cuando hablamos de tierras cultivables, se toman en cuenta las condiciones tecnológicas en el año considerado, o sea, son las tierras de buen temporal, de humedad o irrigables con pequeñas obras de infraestructura a lo largo de los ríos. La enorme mayoría de las tierras que luego se incorporaron a los modernos distritos de riego se consideraban, en 1926, como tierras no cultivables, aptas solamente para la ganadería extensiva o para la explotación forestal.

No deja de ser impresionante constatar que los extranjeros controlaban, en 1926 , el $53.83 \%$ de las tierras cultivables del estado. Su presencia en los municipios de Ahome, Culiacán y Mazatlán es asombrosa. ${ }^{6}$

Se puede decir que el municipio de Ahome estaba en manos de los norteamericanos, esto por dos razones: la instalación de una importante comunidad norteamericana bajo el porfiria to en la desembocadura del río Fuerte y la instalación, en la misma región, de una enorme compañía azucarera, la Unidad Sugar Co., al principio de este siglo.

La comunidad norteamericana había sido fundada en 1886 por el Ing. Albert Kinsey Owen, quien obtuvo del presidente Manuel González y luego de Porfirio Díaz, numerosas facilidades para colonizar tierras en la región de la bahía de Topolobampo, construir allí mismo una ciudad, construir un ferrocarril que vincularía la costa del Pacífico con el de Texas (el Kansas City Mexico y Oriente). Owen pretendía crear una colonia socialista sobre la base de lo que el mismo llamaba "la co-operación integral", que consistía en la abolición de la propiedad privada de la tierra y de los medios de producción, de la moneda y de los impuestos; la sustitución del dinero por la emisión de "crédito de trabajo", cl trabajo colectivo, la administración colectiva de los servicios públicos. Para lograr tal proyecto Owen fundó la Credito Foncier Company, sociedad anónima establecida en Nueva York que debía conseguir los fondos necesarios para llevar a cabo el ambicioso proyecto de colonización. En 1890, Owen tenía derechos sobre 15,360 acres alrededor de la bahía de Topolobampo; 60,000 acres en Los Mochis; 4,437 acres en Mochicahui y 450 en La Logia en donde estaba establecida la colonia. Además, estaba tramitando derechos sobre unos 63 mil acres en Asinahua.7 El mismo

${ }^{6}$ Ibidem., p. 174

' Filiberto Leandro Quintero. Historia integral de la región del rio Fuerte. Ed. El Debate, Los Mochis, Sinaloa, 1978, p. 611. Sobre la experiencia de la colonia socialista norteamericana en Topolobampo véase el libro de F. Leandro Quintero, op. cit., y el libro de Mario Gill: La conquista del valle del Fuerte, Universidad Autónoma de Sinaloa, Colección Rescate, 1983. 
año, el gobierno mexicano le otorgaba un nuevo contrato que le autorizaba a deslindar los terrenos baldíos a uno y otro lado de la línea férrea, aún por construir, en una extensión de $60 \mathrm{~km}$ dentro de los estados de Sinaloa y Sonora, y de $30 \mathrm{~km}$ en Chihuahua y Coahuila. ${ }^{8}$

Sin embargo, la construcción del ferrocarril sufrió muchos retrasos; por otro lado, no era la intención de Owen y de sus colonos deslindar terrenos para acaparar tierras. Eran hombres trabajadores que lo arriesgaron todo para levantar una colonia socialista. Después de muchos esfuerzos su proyecto fracasó. Al principio del siglo no quedaba gran cosa del proyecto socialista, pero sí se habían instalado algunos centenares de familias norteamericanas en la región, que empezaban a levantar una agricultura comercial moderna, con la introducción del riego y tecnología moderna. Gracias a su impulso, las tierras áridas del norte del estado se transformaban poco a poco en tierras de cultivo.

\section{CUADRO 2.}

\begin{tabular}{lcc}
\hline $\begin{array}{l}\text { Nacionalidad de } \\
\text { los propietarios }\end{array}$ & $\begin{array}{c}\text { Porcentaje de la } \\
\text { superficie de sus } \\
\text { tierras }\end{array}$ & $\begin{array}{c}\text { Porcentaje del valor } \\
\text { de sus tierras }\end{array}$ \\
\hline Mexicana & 79.09 & 62.16 \\
Norteamericana & 16.34 & 32.65 \\
Española & 1.29 & 2.36 \\
Alemana & 2.41 & 1.67 \\
Inglesa* & $\ldots .$. & 0.44 \\
Francesa & 0.30 & 0.37 \\
Suiza & 0.51 & 0.30 \\
Italiana* & $-\cdots$ & 0.05 \\
T O T A L & 100.00 & 100.00 \\
\hline
\end{tabular}

FUENTE: Departamento de la Estadística Nacional. Sonora, Sinaloa y Nayarit. México, D.F., Imprenta Mundia, 1928.

* El porcentaje de superficie correspondiente a las nacionalidades inglesas e italianas es de 0.06 .

Mario Gill, op. cit., p. 47. 


\section{CUADRO 3.}

\begin{tabular}{lcc}
\hline Municipios* & $\begin{array}{c}\text { Propiedad de } \\
\text { mexicanos/ha. }\end{array}$ & $\begin{array}{c}\text { Propiedad de } \\
\text { extranjeros/ha. }\end{array}$ \\
\hline Ahome & 29,106 & 76,340 \\
Angostura & 13,805 & 550 \\
Concordia & 19,635 & $\ldots$ \\
Culiacán & 75,732 & 41,264 \\
Escuinapa & 9,020 & 2,200 \\
El Fuerte & 5,830 & $\ldots$ \\
Guasave & 33,121 & 1,878 \\
Mazatlán & 41,250 & 10,362 \\
Mocorito & 8,690 & 5,500 \\
Rosario & 8,250 & 1,650 \\
Sinaloa & 15,153 & $\ldots$ \\
\hline
\end{tabular}

FUENTE: Departamento de la Estadística Nacional; Sonora, Sinaloa y Nayarit. México D.F., Imprenta Mundial, 1928, p.174.

* No hay datos para los municipios de Badiraguato, Cosalá, Choix, Elota y San Ignacio.

La otra razón que explica la presencia de los norteamericanos en cl valle del Fuerte es la creación del ingenio de Los Mochis; veremos brevemente, en el siguiente apartado, cuál ha sido su historia.

En el municipio de Culiacán la importancia de la presencia norteamericana se debe a la actividad de la Sinaloa Land Company, con sede en Nueva York, que se dedić, entre 1904 y 1910 , a deslindar tierras y obtener concesiones de colonización del gobierno porfirista. Esta compañ́a compró al Ing. Martínez de Castro el traspaso de diferentes derechos de deslinde que amparaban grandes superficies en la margen derecha del río Culiacán y obruvo concesiones nuevas, a veces en asociación con los grandes terratenientes de la 
region.9 Por ejemplo, el Ing. Nelson Rhoeder, el apoderado general de la compañía en Sinaloą, obtuvo una concesión para colonizar tierras en la margen izquierda del río Culiacán y logró interesar a los hermanos Almada, dueños del ingenio "La Primavera" de Navolato a participar en este proyecto. Los Almada aportaron, entre otros bienes, 9,962 hectáreas para la creación de la colonia Culiacán. En 1910, debido a dificultades financieras, los hermanos Almada establecerion con la Sinaloa Land Co. un contrato de promesa de venta del ingenio "La Primavera" y de 48,000 hectáreas por la cantidad de 3‘250,000 pesos. Debido al estallido de la Revolución este contrato no llegó a realizarse. Sin duda, la Sinaloa Land Co. fue un factor importante para la instalación de agricultores - a veces pequeños agricultores como en el caso de la colonia Culiacán- y de compañías estadounidenses en el centro del estado.

Otro antecedente que permite explicar la presencia norteamericana en este municipio es la concesión que se otorgó a una compañía estadounidense de Boston para construir, en 1883, el ferrocarril que debía vincular la ciudad de Culiacán con la bahía de Altata; probablemente con la idea de hacer de este lugar un puerto capaz de rivalizar con Mazatlán y Guaymas. Con la construcción de este ferrocarril la compañía adquiría los derechos de deslinde y de colonización que otorgaban las leyes porfiristas. 10

Finalmente, en el municipio de Mazatlán, la importancia de tierras en manos de norteamericanos se debía a la presencia de un numeroso y poderoso grupo de comerciantes y mineros en este puerto. Si bien no tenemos datos precisos sobre el sector minero, sabemos que las principales minas pertenecŕan a compañías estadounidenses tal como las famosas minas del Rosario de la Wohler, Bartning Sucs., que explotaba el oro, la plata y el cobre (en el municipio de Rosario), o de Guadalupe de los Reyes, en el municipio de Cosalá, que explotaba oro y plata con un valor de más de un millón de pesos anuales al iniciar este siglo. 11

En la ciudad de Mazatlán, principal puerto mexicano de la costa del $\mathrm{Pa}$ cífico en el siglo XIX, y que empezó a ser desplazado por el puerto de Guaymas despućs de la Revolución, el capital extranjero controlaba totalmente el comercio internacional. En ello el capital norteamericano tenía una participación significativa. También en el comercio regional predominaba el capital extranjero; esto se puede medir por el monto de los giros mercantiles regis-

\footnotetext{
- Se sabe que por los aǹos 1880-85 la Secretaria de Agricultura y Fomento otorgó al Ing. Mariano Martínez đe Castro una cancesión que le permitió deslindar las tierras que iban del poblado de Las Flores, a $6 \mathrm{~km}$ al poniente del centro de Culiacán, hasta la bahia de Altata, ubicada a más de $40 \mathrm{~km}$ de distancia.

10 José Torres Angulo, La lucha por la tenencia de la rierra en Sinaloa, s. e., México, 1975.

"La Wohler Bartning Suc, era dueña de la principal casa comercial de Mazatlán que se llamaba "La voz del pueblo". También era socio de la destileria Lavalle que refinaba el alcohol del ingenio La Florida de una de las grandes familias terratenientes del norte del estado, la familia Zakany.
} 
trados de acuerdo con la nacionalidad de las compañías que los emitían, en el curso del año de 1926 en cl puerto de Mazatlán (cuadro 4).

CUADRO 4. Nacionalidad y monto de los giros mercantiles de más de 5,000 pesos registrados en Mazatlán en 1926.

\begin{tabular}{lcc}
\hline Nacionalidad & $\begin{array}{c}\text { Monto de los } \\
\text { giros en pesos }\end{array}$ & \%o \\
\hline Chinos y japoneses & $2,915,000$ & 29.84 \\
Alemanes & $2,735,000$ & 27.99 \\
Norteamericanos & $1,970,000$ & 20.16 \\
Mexicanos & $1,190,000$ & 12.18 \\
Españoles & 700,000 & 7.17 \\
Sirio libanescs & 225,000 & 2.30 \\
Otras nacionalidades & 35,000 & 0.36 \\
Totales & $9,770,000$ & 100.00 \\
\hline
\end{tabular}

FUENTE: Departamento de la Estadística Nacional. Sonora, Sinaloa y Nayarit, México, D.F., Imprenta Mundial, 1928 , p. 376.

Fue gracias a las facilidades otorgadas por el porfiriato que el capital comercial y minero extranjero se desplazó hacia la agricultura en el final del siglo XIX y principios del XX. No solamente los mineros y comerciantes invirtieron en tierras cercanas al puerto, sino que pronto las encontramos en todo el estado.

\section{LA PRODUCCION}

\section{a) La caña de azúcar}

La abolición del esclavismo en los Estados Unidos provocó una grave crisis cconómica en las plantaciones del sureste de este país, que afectó la producción algodonera y azucarera. En las últimas décadas del siglo pasado muchos ingenios dejaron de funcionar.

Esta crisis facilitó el crecimiento de la producción azucarera en Sinaloa, en donde existían buenas condiciones para crear nuevos negocios agroindus- 
triales. Había tierra y agua en abundancia; aunque en pequeñas cantidades, la caña de azúcar ya se cultivaba desde la colonia. A fines del siglo XIX habŕa capital disponible en la región para ser invertido en nuevos negocios. Las compañías mineras y comerciales, instaladas esencialmente en Mazatlán, buscaban ampliar su campo de inversión; y hemos visto que buena parte de este capital era norteamericano. También directamente desde los Estados Unidos muchos inversionistas se interesaban por crear negocios en el estado.

La gran ventaja de Sinaloa sobre los estados del centro y sureste del país era la casi inexistencia de poblaciones indígenas; la hacienda y luego las empresas agrícolas modernas pudieron extenderse con gran facilidad porque no había contradicción fuerte, con las tierras indígenas. El principal problema era precisamente la falta de población indígena para tener la mano de obra necesaria, pero los azucareros supieron resolver esto, ofreciendo buenos sueldos a los trabajadores que empezaron a migrar de las sierras circunvecinas y luego de otros estados.

Es en estas condiciones que surgen los grandes ingenios azucareros de Sinaloa. Uno de ellos, el más grande, fue construido por un norteamericano, Benjamin Francis Jonhston, en el valle del Fuerte, sobre las mismas tierras que habían colonizado los socialistas de la colonia de Owen.

Aunque existen diferentes versiones sobre los orígenes de Johnston, nos parece que la versión más acertada es la siguiente: Benjamin Francis era un joven decidido a hacer fortuna en los negocios para los cuales tenía mucha facilidad; llegó a Sinaloa cuando tenía unos 25 años para ofrecer a los hacendados azucareros del estado la venta de un ingenio que una compañía de Bâton Rouge, Louisiana, le había ofrecido a comisión. No sabemos si pudo vender el ingenio, pero en 1893 establecía una sociedad con uno de los principales caciques de la región, don Zacarías Ochoa, que desde hacía algún tiempo cultivaba caña de azúcar.

La nueva sociedad entre Johnston y Ochoa se llamó El Aguila Sugar \& Refining Co., con un capital de 250,000 pesos. Johnston aportaba el ingenio, Ochoa los cañaverales. El primero recibiría, probablemente de acuerdo con el capital aportado, el $60 \%$ de las utilidades, el segundo, cl $40 \%$. Se firmó un contrato leonino entre ambos socios, que marcó la ruina del terrateniente y el principio de la inmensa fortuna del joven industrial norteamericano: "En el contrato suscrito entre BFJ y el hacendado, éste se comprometía a entregar cinco mil toneladas de caña durante el primer año, a razón de $\$ 4.00$ /tonelada, pero se obligaba a aumentar mil toneladas cada año. En caso de incumplimiento, el agricultor pagaría al industrial $\$ 1.00$ por cada tonelada que dejara de entregar de acuerdo con el convenio".12

12 Mario Gill, op. cil., p. 62. 
Establecido el contrato y funcionando la nueva sociedad, la principal preocupación de Johnston fue ampliar el pequeño ingenio del Aguila.13 En 1984 organizó en los Estados Unidos una sociedad de la cual era presidente, la Sinaloa Sugar Company, con un capital de 500,000 pesos. Compró en Aberden, Louisiana, maquinaria de segunda mano para incrementar la capacidad de molienda del ingenio a 200 toneladas diarias.

El joven norteamericano demostró ser mucho más hábil en negocios que su viejo socio. Don Zacarías no lograba incrementar su producción de caña para cumplir con el contrato. Al cabo de 10 años tuvo que entregar su hacienda a Johnston en pago de sus deudas.

Mientras tanto, Johnston buscaba despojar a los colonos de la Credit Foncier of Sinaloa, del canal de Taste, el único canal de irrigación en la región, que habían construido en 1891 y 1892 , de sus tierras que conformaban la zona de riego más grande del valle del Fuerte. Aprovechando dificultades internas de la colonia norteamericana, compró a precio irrisorio las acciones de la Kansas Sinaloa Investment Co. que financiaba el proyecto de la colonización desde 1889 y que habra financiado la construcción del canal del Taste. Al controlar la mayor parte de las acciones de la compañóa, exigió que se le entregaran el canal y las tierras.

Ya dueño de la ticrra y del agua, Johnston echó a andar, en 1902, lo que fucra el proyecto de su vida: la construcción del ingenio de Los Mochis. Este ingenio sería pronto el más grande de todo el país.

En esa ocasión la maquinaria se compró en Florida. Aunque inicialmente el nuevo ingenio tuvo la misma capacidad que "El Aguila", se planificó desde un principio para que fuera un enorme complejo agroindustrial. Los campos de cultivo fueron trazados a cuadrícula, en lotes de 100 hectáreas, conformados por los canales de derivación que se desprendían del canal de Taste (ahora liamado canal de Los Mochis). Johnston creó entonces la United Sugar Company (USCO) que integraba los ingenios de Los Mochis y de "El Aguila" en una sola sociedad.

Había, al principio del siglo, una verdadera fiebre de producción de azúcar en todo el país; Sinaloa empezó a destacarse como estado azucarero. La competencia en tre los ingenios del estado era muy fuerte, pero poco a poco la United Sugar Co. eliminó o absorbió a los otros ingenios que funcionaban en la region, todos con una capacidad de molienda de 200 toneladas diarias.

13 La maquinaria de este ingenio se compró en los Estados Unidos en 1892. 
Sin embargo, este rápido crecimiento de la producción de azúcar provocó una crisis de sobreproducción. A partir de que México se adhirió a la Convención de Bruselas, el gobierno tuvo que bajar los aranceles que gravaban la importación del azúcar. Esta medida perjudicó a los azucareros de Sinaloa y Tamaulipas, tanto más, que para esta fecha cl sector azucarero norteamericano había salido de la crisis originada por la abolición de la esclavitud, gracias a la concentración de un capital y la modernización de su proceso productivo. Entre 1906 y 1908 se incrementaron sicte veces las importaciones de los Estados Unidos a México, pasando de 333 a 2,369 toneladas. Frente a la gravedad del problema, y a petición de la Unión Azucarera de Sinaloa, el gobierno elev6 otra vez los aranceles -de 2.5 por $\mathrm{kg}$ a $5 \mathrm{c}-\mathrm{de}$ tal manera que, otra vez, para el consumidor mexicano el azúcar nortcamericano era más caro que el azúcar producido en Sinaloa. La medida fue efectiva, ya que en 1909 las importaciones bajaron a 973 toneladas. 14 En Sinaloa esta medida beneficiaba esencialmente a cuatro ingenios: el ingenio de El Dorado y el de Navolato, en el valle de Culiacán, y los ingenios de El Aguila y de Los Mochis -el último entonces cra ya cl más grande del estado- ambos propicdad de Benjamín F. Johnston.

A pesar de estas medidas proteccionistas y del contrabando de azúcar hacia California, la United Sugar Co. se mantuvo con dificultad por la falta de mercado. Se vio obligada a vender su azúcar en los estados del centro del país, compitiendo a precio de dumping con el azúcar de Morelos y Veracruz. El costo de producción de Los Mochis era de $14 \mathrm{c}$ por kilogramo, mientras que el precio de venta oscilaba entre 14 y 15 centavos el kilo. El ingenio tenía un déficit permanente de 60,000 a 70,000 pesos. ${ }^{15}$ Parecía que el genio de Johnston para realizar buenos negocios y especular, no podía evitar el fracaso de la United Sugar Co. La situación llegó a ser tan difícil que el Banco Nacional, con el cual operaba, mandó a un auditor para controlar las operaciones financieras del ingenio.

La Revolución Mexicana vino a salvar al sector azucarero sinaloense porque la destrucción de los ingenios de Morelos les abrió nuevas posibilidades en el mercado nacional. Después, el estallido de la Primera Guerra Mundial abrib nuevas posibilidades en el mercado internacional por la escasez de producción de la remolacha azucarera en los países europeos en conflicto. Después de 1914 el precio internacional del azúcar subió de cinco dólares el saco a 18 dolares. Las propias compañias norteamericanas mandaban a sus agentes a Sinaloa para comprar la producción azucarera.

\footnotetext{
14 La Unión Azucarera de Sinaloa se creó en 1903 con la participación de los principales ingenios del valle del Fuerte: el ingenio La Flurida, de Zakan y sucesores; la Constancia, de don Francisco Orrantia y Sarmiento. El Aguila y Los Mochis. de la United Sugar Co. Esta unión tuvo corta vida porque la USCO monopolizó pronto la producción del azúcar en el valle. Ma. Gisela Espinoza Damián. La industria azucarera en Morelos durante el porfirismo. Tesis de licenciatura, Facultad de Ciencias Politicas y Sociales, UNAM, 1984, pp. 119.

is Filiberto L. Quintero, op. cit., p. 546.
} 
La década de la Revolución marcó el auge de los negocios de Johnston. En 1917 decidió reorganizar sus empresas. Desapareció la United Sugar Co. y se creó la United Sugar Companies, S.A., con un capital inicial de cuatro millones de pesos. Esta nueva compañía reagrupaba todos sus negocios y se creaba por una duración de cincuenta años. La USCO, S. A. era dueña de los dos ingenios azucareros, de sus tierras, y de las plantas generadoras de electricidad que surtían a la ciudad de Los Mochis. Fue propietaria de los negocios que Johnston iba creando: la Compañía Explotadora de las Aguas del Río Fuerte (creada en 1919); la Compañía del Ferrocarril Mexicano del Pacífico; la Compañía Eléctrica de Los Mochis (creada en 1926), la Compañ́a Agrícola de Los Mochis (creada en 1925 para adquirir y administrar propiedades rústicas y urbanas), la Compañía del Sufragio, La Rosario Grijalvo y Cía., la Rafael G. Ibarra y Cía., la Compañáa Ágrícola del Río Fuerte, la Compañía Agrícola de Constancia.

En la década de los veinte Johnston había triunfado, dominaba la economía del valle del Fuerte. En 1920 cerró el ingenio "El Aguila" para concentrar en Los Mochis la producción del azúcar, de tal manera que este ingenio era en 1926 el ingenio más grande del país con una producción anual de azúcar de 19,000 toneladas. 16

Fue en ese tiempo cuando Johnston decidió echar a andar dos nuevos proyectos, tal vez más ambiciosos aún que la creación del ingenio de Los Mochis: la construcción de una enorme presa hidráulica, la presa de Balajoqui, para irrigar 500 mil hectáreas del valle del Fuerte y generar electricidad, y la adquisición del ferrocarril Kansas City México Oriente, creado por Albert $\mathrm{K}$. Owen a fines del siglo pasado, para terminar la línea que vincularía el puerto de Topolobampo con Kansas City, en Texas. Sin embargo, no logró llevar a cabo estos últimos proyectos por la oposición del gobierno mexicano, que empezaba a preocuparse seriamente por la enorme riqueza y el poder que cjercía el norteamericano en el Noroeste. En 1924, el general Alvaro Obregón se opuso terminantemente a que se le diera la concesión necesaria para la construcción de la presa. De haberle dado la autorización, Johnston se hubiera convertido en el virtual dueño de todo el valle.

En 1928 adquirió el ferrocarril que solamente tenía unos $100 \mathrm{~km}$ de vías, de Topolobampo a la ciudad de El Fuerte. Aún pensaba poder construir la presa de Balajoqui, con la cual se debra generar la electricidad para la electrificación de la línea férrea. Sin embargo, la presa nunca se hizo17 y parece

\footnotetext{
- En 1926 los principales ingenios eran: "Los Mochis", con una producción de 19,000 toneladas de azúcar; "El Potrero" Veracruz), con 14,000 toneladas de azúcar; "Atencingo" (Puebla), con 11,000 toneladas de azúcar, "San Cristóbal" veracruz), con 10,700 toneladas de azúcar: "El Dorado" (Sinaloa), con 9,000 toneladas de azúcar; y "La Primavera" Vavolato, Sinaloa), con 8,000 toneladas de azúcar. Los demás ingenios del país producían normalmente menos de 3,000 ssoeladas; muchos, menos de 1,000. Unión Nacional de Productores de Azúcar, S.A., El desarrollo de la industria zescurera en México durante la primera mitad del siglo XX. México, 1950, pp. 44-47.

El Gobierno mexicano hizo en este mismo lugar la presa Miguel Hidalgo y Costilla, terminada en 1956, que permitió zgor unas 200,000 hectáreas en el valle del Fuerte y el valle del Carrizo.
} 
que Johnston perdió interés en el proyecto del ferrocarril que fue propiedad de la USCO sin que se le hiciera mejora alguna hasta 1940, cuando el gobierno de Cárdenas decidió comprarlo.18

\section{b) El tomate1 9}

A partir de 1907 el norte de Sinaloa quedó vinculado por ferrocarril (el "Sud Pacífico", que venía desde la ciudad de Nogales) con los Estados Unidos. Los efectos de esta nueva vía de comunicación se hicieron sentir inmediatamente en la economía regional.

Una vez más fueron los norteamericanos de la antigua colonia socialista los que tuvieron la iniciativa de emprender un nuevo negocio: el cultivo de hortalizas, esencialmente del tomate, para exportación en los Estados Unidos. Sinaloa se beneficiaba de una gran ventaja ya que podía cultivar hortalizas en invierno cuando era imposible hacerlo en California, que era entonces prácticamente el único estado productor de legumbres en los Estados Unidos.

Algunos colonos se pusieron en contacto con una compañía de Los Angeles, la Kleim Fruit Co., para distribuir cl tomate. Poco después esta compañía tuvo problemas pero otras se interesaron en el negocio y a pesar de las dificultades para controlar la calidad de la fruta y su adecuada conservación en el transporte se mantuvo la exportación hasta el estallido de la Revolución. Con la lucha armada muchos agricultores del valle, principalmente extranjeros, tuvieron que abandonar sus ranchos; además el Sud Pacífico dejó de funcionar normalmente para prestar sus servicios a las fuerzas constitucionalistas. En estas condiciones se suspendió la exportación de tomate.

Apenas reestablecida la paz en la región, se reiniciaron el cultivo y la exportación de esta fruta. En 1916 la Mexican Arizona Trading Co. (MATCo.) y su subsidiaria mexicana, la Matco-Boyd y Cía., exportan otra vez el tomate hacia Nogales. La Matco creció rápidamente y pudo resistir a la crisis del ciclo agrícola de 1919-20, provocada por el levantamiento de Agua Prieta, que dificultó otra vez el servicio adecuado del Sud Pacífico.

El éxito de la Matco se debía en gran medida a las modernas formas de organización que adoptó. La compañía refaccionaba a los agricultores con las

\footnotetext{
18 Por otro lado, sabemos que en el sector azucarero sinaloense el capital norteamericano tenia también intereses en el ingenio "La Primavera" de Navolato. Por dificultades financieras, al principio del siglo los hermanos Almada, dueños del ingenio, entraron en sociedad con diferentes capitalistas de Nueva York creando la Almada Sugar Refineries Company. Hasta fines del siglo pasado el ingenio exportaba su azúcar a California. Para construir el ingenio de El Dorado, en 1898, se compró la maquinaria del ingenio "San Claudio", en Florida. Se embarcó toda la maquinaria en un velero alemán de una capacidad de 2000 toneladas para dar la vuelta al cabo de Hornos y llegar, después de un viaje de meses, al lugar escogido para desembarcar la maquinaria y trasladarla hasta el nuevo ingenio.

19 Para este inciso se utilizan esencialmente los datos de Mario Gill, op. cit.
} 
semillas e insecticidas importados de los Estados Unidos (aún no se utilizaban fertilizantes), y con dinero con una tasa de interés del 6 al $8 \%$ anual. $\mathrm{Si}$ era necerario, también proporcionaba los aperos agrícolas, los animales y aun la tierra. Compraba la cosecha o la tomaba a consignación con un margen del $10 \%$ sobre las ventas. Los años eran buenos, la exportación de hortalizas dejaba a la compañía enormes ganancias, que le permitían invertir gran parte de su capital en la producción sin pedir más garantía a los productores que el empeño de su palabra.

El negocio era tan bueno que la Miers, Darling \& Hinton Co., que había fracasado diez años antes en este mismo ramo, decidió en 1921 reiniciar sus actividades en la región. De 1921 a 1927 fue la época de oro del tomate. Fueron buenos años de producción, el mercado estadounidense era excelente, ya que aún los productores de Florida no hacían competencia seriá a los productores de Sinaloa. El ferrocarril había ḿodernizado sus carros frigoríficos, el arancel norteamericano era muy bajo, sólo de medio centavo de dólar por libra. El $60 \%$ de la producción tomatera de Sinaloa estaba controlada por la Matco y la Miers, Darling \& Hinton Co.; el resto se repartía entre numerosos comisionistas estadounidenses con oficinas en Nogales.

La actividad tomatera provocó un desarrollo económico sin precedente porque benefició a muchos pequeños productores. Se inició en el norte del estado pero llegó pronto hasta el valle de Culiacán. Se empezaron a construir empaques - aún no tenían nada qué ver con los empaques modernos que conocemos ahora- utilizando la tecnología norteamericana. Se construyeron enormes hangares para instalar largas bandas mecánicas en donde trabajaban los empacadores. Se importaba la maquinaria por el mismo tren que se llevaba el tomate hacia Nogales.

Para 1927, gracias a la intensa actividad de las compañías exportadoras, se cultivaban en el estado 17,800 hectáreas de tomate con una producción total de 34'176,000 kg. El mismo año se producían en Sonora 3'850,695 kg, solamente el $11 \%$ de la producción sinaloense. 20

Sinaloa fue el primer estado en cultivar el tomate y ha sido, desde un principio, el principal productor de esta fruta. En 1924 se habían producido en todo el estado $24^{\prime} 285,441 \mathrm{~kg}$ de tomate por un valor de $6^{\prime} 632,225 \mathrm{pe}$ sos; en 1926 se producían $34^{\prime} 269,736 \mathrm{~kg}$ por un valor de $11^{\prime} 228,219$ pesos, o sea que en dos años el valor de la cosecha había crecido en un $59 \% .21$

Un crecimiento tan fuerte y anárquico de la producción debŕa conducir inevitablemente a una terrible crisis de sobreproducción que empezó en el

\footnotetext{
${ }^{20}$ Departamento de la Estadistica Nacional, op. cit., pp. 166 a 169.

It Ibidem, pp, 172-173.
} 
ciclo agrícola de 1926-1927. En este ciclo el tomate sinaloense entró por primera vez en competencia con el tomate de Florida. En ambas regiones la cosecha había sido excelente, hubo sobreproducción, los precios se derrumbaron. A partir de esta fecha Sinaloa y Florida se disputaron el mercado estadounidense e internacional.

Otra vez la Miers, Darling \& Hinton tuvo mala suerte. En 1927 apenas alcanzó una venta de 330,000 dólares cuando los agricultores le adeudaban unos dos millones de dólares. La compañía nunca pudo recuperarse, cayó en bancarrota y se retiró del mercado.

La Matco fue una de las pocas empresas que resistió a la crisis que se prolongó luego por los efectos de la crisis internacional de 1929 y el aumento de los aranceles norteamericanos. La American Fruit Growers, de California y la Stearns Packing Company, de Los Mochis, también per'sistieron a pesar de las dificultades.

A pesar de tantos fracasos subsistían en el valle del Fuerte 60 empacadoras. Pero los tiempos eran otros. Poco a poco desaparecieron los pequeños productores; se concentró la producción en manos de nuevos empresarios hortícolas que lograron controlar la producción, la conservación y la distribución de las hortalizas gracias a fuertes inversiones de capital.

Para 1930 las condiciones del mercado habían cambiado. Después de la crisis de $1929 \mathrm{cl}$ consumo norteamericano había bajado, los productores de Florida entraban en competencia con los de Sinaloa; para proteger su producción el gobierno estadounidense elevó las tarifas arancelarias de medio centavo de dólar por libra a tres centavos. Además, el propio gobierno mexicano empezó a gravar la producción hortícola. El cultivo de las hortalizas para su exportación permitiría la realización de enormes fortunas, pero ya no eran los tiempos de la aventura tomatera financiada por hábiles y arriesgados hombres de negocios norteamericanos.

La competencia entre los horticultores de Sinaloa y de Florida -que producen hortalizas de invierno para el mercado estadounidense-llegó en 1933 a un punto crucial. Para protegerse, los productores de Florida, a través de sus representantes en el Senado y en la Cámara de Diputados, pidieron a la Comisión de Tarifas de Washington que se aplicara la ley antidumping de 1921 a la producción hortícola sinaloense. La medida concreta consistía en elevar las tarifas arancelarias para impedir la entrada de los productos mexicanos. En su defensa, los horticultores sinaloenses argumentaron que no sólo no aplicaban un precio de dumping a sus productos, sino que el $70 \%$ del dinero producido por sus hortalizas quedaba en manos de compañfas norteamericanas, "como tributo con que contribuye el productor mexicano al acre- 
cimiento de la riqueza pública de este país". $22 \mathrm{El}$ argumento era fuerte: "si México recibe algún beneficio de la exportación de tomates a los Estados Unidos, mucho mayor es aún el que reciben los Estados Unidos mismos". 23 Efectivamente, los intereses económicos de compañías norteamericanas estaban tan fuertemente ligados a la suerte del tomate mexicano, que la Comisión de Tarifas declaró que no había dumping; y que no se elevarían más las tarifas arancclarias. Poco a poco el tomate sinaloense se vendía en todos los Estados Unidos y penetraba hasta Canadá.

\section{EL REPARTO AGRARIO Y LAS EMPRESAS AGRICOLAS NORTEA- MERICANAS}

El reparto agrario en Sinaloa no cobró importancia hasta el cardenismo, pero en este período se transformó definitivamente la tenencia de la tierra con el reparto de 622,135 hectáreas de un total de un poco más de dos millones de hectáreas repartidas hasta la fecha. Las regiones más afectadas fueron las de mayor potencial productivo. De los 17 municipios que hay en el estado, aquellos cuatro en donde se ubicaban las tierras más fértiles y los productos más rentables -hortalizas, caña de azúcar y garbanzo- se repartieron 407,671 hectáreas, o sea el $65.52 \%$ de las tierras repartidas por Cárdenas. 24 Evidentemente, este reparto afectó en gran medida a agricultores y compañáas norteamericanas que, por ser empresas dinámicas, se encontraban siempre en tierras de buena fertilidad, en tierras de riego por medio de bombas y canales de irrigación que ellas mismas habŕan instalado.

El 9 de diciembre de 1937, por decreto del Gral. Cárdenas, se expropiaron 83,442 hectáreas de la United Sugar Co. para entregarlas a 4,663 ejidatarios. Este decreto fue el resultado de una muy larga y dura lucha entre los trabajadores y la compañía. Esta lucha se inició en 1914 cuando algunos trabajadores pidieron mejores condiciones de trabajo. A partir de 1934, aprovechando la favorable coyuntura creada por el cardenismo, los trabajadores intensificaron su lucha. Las huelgas y paros de labores se sucedieron a un ritmo impresionante, pidiendo mejores condiciones de trabajo, las mismas desde 1914. En marzo de 1937 los trabajadores constituyeron la Union de Comunidades Agrarias del Norte de Sinaloa, para solicitar las tierras de la USCO. Propusieron a Cárdenas la creación de la Sociedad de Interés Colectivo Agrícola Ejidal (SICAE) para producir colectivamente, entre todos los ejidos beneficiados por el reparto, la caña de azúcar que necesitaba el ingenio. El presidente de la república aceptó el plan y firmó el decreto expropiatorio. Así, la

\footnotetext{
${ }^{22} \mathrm{El}$ dumping consiste en vender sus productos por debajo de sus costos de producción; o en su defecto, realizar ventas en el mercado de exportación a precios inferiores que en $\mathrm{el} \mathrm{mercado} \mathrm{nacional.}$

23 Asociación de Agricultores del rio Culiacán; Sinaloa-Florida, medio siglo de controversia (1930-1979), Boletín Agricola No. 2, mayo-junio de 1979, Culiacán, Sinaloa, p. 62.

it Estos municipios son: Ahome, El Fuerte, Sinaloa y Culiacán.
} 
USCO perdía la mayor parte de sus tierras, sus mejores tierras y los cañaveralcs, pero conservaba cl ingenio y sus diferentes compañías. Luego se le expropió el ferrocarril y la compañía de luz y teléfono.

Benjamin Franklin Johnston no conoció la expropiación de sus tierras. Murió meses antes en la ciudad de Hong Kong. 25 Según Mario Gill, veía con buenos ojos la expropiación, siempre y cuando se asegurara el adecuado abastecimiento de caña de azúcar para su ingenio. ${ }^{26}$ De esta manera el ingenio se quitaba de problemas con sus trabajadores, que se transformaban en productores de caña con la obligación de surtir al ingenio. El arreglo era bastante bueno para la USCO, ya que el verdadero negocio se encontraba en el ingenio más que en los cañaverales. La formación de la SICAE y la obligación de producir caña respondían a esta necesidad.

Así, se expropiaron muchas tierras en manos de norteamericanos; pero también muchos, al igual que los hacendados mexicanos, no esperaron la expropiación y decidieron vender a colonos. A partir del cardenismo y hasta la década de los cincuenta existieron excelentes condiciones para que pequeños agricultores pudieran comprar tierras. Por ejemplo, en 1934 unos pequeños agricultores -minifundistas- del pueblo de Pericos, en el municipio de Culiacán, fueron afectados para crear un ejido. Un grupo de veinte de ellos se organizó para comprar tierra a la Charles F. Vandewater y crear la colonia Hidalgo, en la cercanía del puerto de Altata. Esta compañía ganadera norteamericana de Los Angeles había comprado enormes superficies a la Sinaloa Land Co. y tenía sus tierras divididas en diferentes haciendas, como la hacienda de las Trancas, de más de 9,000 hectáreas, en las cuales criaban ganado y cultivaban maíz y frijol.27

Para vender así tierras a pequeños agricultores se seguían los lineamientos legales de la ley federal de colonización y la propia Secretaría de Agricultura supervisaba la transacción. En realidad, las condiciones de compra eran inmejorables. Los compradores, llamados colonos porque el contrato de compra-venta obedecía en términos generales a las normas de la mencionada ley, recibieron cada uno un lote de 50 hectáreas sin desmontar, por un valor de 5,000 pesos. Las tierras se pagaban en 10 años. Los dos primeros años no se pagaba nada para que los colonos pudieran empezar a desmontar y obtener sus primeras cosechas. A partir del tercer aino se pagaba un $12 \%$ anual del valor total del predio, hasta liquidar los 5,000 pesos. No se cobraban réditos. $28 \mathrm{Al}$ terminar de pagar las tierras, el Departamento de Asuntos Agrarios y Colonización entregaba sus títulos de propiedad a los colonos que se transformaban, en términos de las leyes agrarias, en pequeños propietarios.

\footnotetext{
25 Johnston, enormemente rico, tenia af́os de no encabezar personalmente sus negocios. Pasaba su tiempo en largos viajes a través del mundo. Murió en uno de estos viajes, el 9 de marzo de 1937.

26 Mario Gill, op. cit., p. 150.

"Otra compañía similar era la Victor Twist, también de capital estadounidense.

${ }^{28}$ En esta época una hectárea de buena tierra de cultivo valia 150.00 pesos.
} 
Después del reparto cardenista se prosiguib el reparto agrario con la apertura de los distritos de riego y la aplicación de la Ley Federal de Aguas. A lo largo de estos años las compañías norteamericanas salieron poco a poco del sector de la producción agrícola.

Al principiar la segunda mitad de este siglo parecía que por fin México había logrado los objetivos que se planteaba en los años posteriores a la Revolución: la mexicanización del sector agrícola en los estados fronterizos, no sólo como medida económica para abrir nuevas tierras al cultivo, sino como medida política para fortalecer la identidad nacional mexicana (hispánica) y contrarrestar la influencia norteamericana en la región. Aunque nunca se logró provocar un regreso masivo de los mexicanos instalados en los Estados Unidos, el reparto agrario sí logró crear una capa muy importante de pequeños productores, ejidatarios y legítimos pequeños propietarios. Estos nuevos productores modernos fueron organizados gremialmente en el Partido Revolucionario Institucional -a través de la Confederación Nacional Campesina, para el sector ejidal; y la Conferederación Nacional de la Pequeña Propiedad, para el sector privado- y fueron los agentes del desarrollo agrícola del Noroeste. El objetivo político inmediato se había cumplido.

En el plan económico, con el desarrollo tecnológico y la transnacionalización del capital, las cosas se volvieron mucho más complejas. Aparentememente, con el reparto agrario se había mexicanizado la agricultura, pero al cabo de la vuelta de rueda el capital estadounidense regresó con mayor fuerza y sofisticación a controlar el desarrollo económico del país. Con el desarrollo agroindustrial la producción agrícola se transformaba en el sector menos importante de la producción alimentaria. Como algunos autores la caracterizaron: es ahora el eslabón menos importante dentro de la cadena agroindustrial. Controlar directamente la agricultura ya no tenía ninguna importancia, bien lo había presentido Johnston; lo importante era controlar la industria agroalimentaria en donde se genera la mayor ganancia y dunde se decide la suerte de la producción agrícola. A partir de la década de los sesenta las agroindustrias internacionales penetraron con tal fuerza, que se puede afirmar que hoy en día no solamente en la región fronteriza, sino en todo el país, la. agricultura mexicana está dominada por el capital agroindustrial extranjero, esencialmente norteamericano. 